\title{
Nurses' Knowledge versus their Performance regarding Chest Physiotherapy for Children in Pediatric Intensive Care Units
}

\author{
Nashat E.Ali****, Osama A. El fiky*; Madiha A. Morsy**; Basma R.Abd El sadek*** \\ * Pediatrics-Faculty of Medicine-Benha University \\ ** Pediatric Nursing - Faculty of Nursing - Ain Shams University \\ *** Pediatric Nursing - Faculty of Nursing - Benha University \\ **** B.Sc. in Nursing Science
}

\begin{abstract}
Aim of the study was to assess the nurses' knowledge versus performance regarding chest physiotherapy provided to children in pediatric intensive care units. Research Design: A descriptive research design was utilized. Settings: The study was conducted at Pediatric Intensive Care Units in Benha city in Benha University Hospital and Benha Pediatrics Specialized Hospital affiliated to Qualubia Governorate. Subjects: A purposive sample included fifty nurses and forty children selected from the previously mentioned settings. Tools: of data collection there were two tools, an observational checklist to assess performance and a structured interviewing questionnaire to assess knowledge. Results: the results revealed that more than three quarters of the studied nurses had unsatisfactory knowledge scores level and more than two thirds of the studied nurses are incompetent regarding performing chest physiotherapy. Conclusion: In Pediatric Intensive Care unit, the studied nurses had unsatisfactory knowledge and are incompetent in performing chest physiotherapy, there was highly statistical significant relation between nurses' performance and their qualification only. While there was highly statistical significant relation between nurses' knowledge and nurses' age, qualification and years of experience. Recommendations: Upgrading pediatric intensive care nurses' knowledge and performance regarding to chest physiotherapy through continuous in-service and in job training education program. Further studies about chest physiotherapeutic techniques performed by nurses on children in pediatric intensive care units are recommended at different settings.
\end{abstract}

Key words: Chest physiotherapy, Pediatric Intensive Care Units, Nurses' performance ,children.

\section{Introduction}

Chest Physiotherapy (CPT) is the term for a group of treatments designed to improve respiratory efficiency, promote expansion of the lungs, strengthen respiratory muscles, and eliminate secretions from the Respiratory System (RS). It is widely used in hospital Intensive Care Units (ICUs) including Pediatric Intensive Care Unit (PICU) to facilitate secretion clearance, improve oxygenation, assist with weaning from Mechanical Ventilation (MV), and to minimize the effects of prolonged bed rest (James , 2016 ).

The objectives of CPT are to prevent or reduce the mechanical consequences of obstructing secretions, such as hyperinflation, atelectasis, maldistribution of ventilation, ventilation/perfusion mismatch and increased work of breathing. Another therapeutic concept focuses on removing infective material, inflammatory mediators, and proteolytic and oxidative activity from the airways and in doing so, it reduces or even 
prevents the inflammatory tissue damage (Mitra, 2008).

Chest physiotherapy consists of various manipulative procedures, mainly postural drainage, chest percussion and vibration. Other procedures that may be utilized include thoracic squeezing, cough stimulation and breathing exercises (Jennifer et al., 2013).

During postural drainage, the pediatric patient is positioned so that the bronchus of a particular segment is as vertical as possible. Gravity pulls the secretions toward a major bronchus or the trachea; the secretions are then either expectorated or suctioned. The child is kept in this position for up to 15 minutes. Critical care pediatric patients and those depending on MV receive postural drainage therapy four to six times daily. Percussion and vibration may be performed in conjunction with postural drainage (Ellie\&Jones., 2015).

Percussion is rhythmically striking the chest wall with cupped hands. It is also called cupping, clapping, or tapotement. The purpose of percussion is to break up thick secretions in the lungs so that they can be more easily removed. Percussion is performed on each lung segment for one to two minutes at a time (Stiller, 2013).

Pediatric Intensive Care Unit nurses provide care for children and adolescents with a wide-range of ailments, which are usually life-threatening illnesses. PICU nurses provide direct and individualized nursing care to the pediatric patients based on the application of scientific nursing principles. CPT may be one of the duties of the PICU nurse which requires good training and understanding of its principles (Patricia et al., 2017).

The nurse should be aware of the pediatric patient's diagnosis as well as the lung lobes or segments involved, the cardiac status, and any structural deformities of the chest wall and spine. Auscultating the chest before and after the procedure helps to identify the areas needing drainage and to assess the effectiveness of treatment (Patricia et al., 2017). Pediatric Intensive Care Unit (PICU) is a highly specialized department found mainly in the tertiary care hospitals. It provides care for children requiring intensive care and monitoring, including medically unstable patients requiring intubation or ventilation, single or multi-organ support, and continuous or intensive medical or nursing supervision. PICU also provides routine planned postoperative care for major surgical procedures, or during some planned medical admissions (Jerithea et al., 2017 )

\section{Aim of the study}

The aim of this study was to assess nurses' knowledge versus performance regarding chest physiotherapy provided to children in pediatric intensive care unit .

\section{Research Question}

1- Are PICU nurses had satisfactory knowledge regarding application of chest physiotherapy for children?

2- Are PICU nurses competent during performing chest physiotherapy for children?

3-Are Socio demographic of nurses have an effect on their performance of chest physiotherapy for children?

\section{Subjects And Method}

\section{Research Design}

A descriptive design was utilized in the current study.

\section{Research Settings}

This study was conducted in Pediatric Intensive Care Units (PICUs) in Benha 
University Hospital and Benha Pediatrics Specialized Hospital

\section{Subjects}

Apurposive sample included 50 nurses providing direct care for children having health deviations in need for chest physiotherapy as a nursing intervention in the previously mentioned setting and purposive sample of 40 children who needed chest physiotherapy and having respiratory diseases

\section{Tools of data collection}

Data were collected by using the following tools:

\section{Tools (I): Observational checklist}

It was adapted from Marry and Patrick. (2009) and used to assess the actual nursing performance in physiotherapy techniques provided to children in PICU which included the most common techniques as percussion, vibration and postural drainage.

\section{Score system of performance:}

All performance related steps were scored as 2 for competent score of performance and 0 for incompetent score of performance.

Total performance score was classified as the following: Competent: $\geq 95 \%$ of total performance score \& Incompetent: <95\%of total performance score.

Tool (II): A structured interviewing questionnaire sheet: It was assessed by nurses' knowledge, It includes the following parts :
Part I: Nurses' characteristics such as age,educational level, years of experience and attendance of previous educational programs in physiotherapy, the mean age of the studied nurses were $28.02 \pm 4.36$ while $46 \%$ of the studied nurses were secondary school nursing and only 30\%,24\% were technical institute and baccelor degree respectively, Regarding to years of experience, the mean years of experience $4.90 \pm 2.00 ., 80 \%$ of the studied nurses were living in rural areas and only $20 \%$ of them were living in urban areas.

Child's characteristics such as age and gender, their diagnosis and age(The mean age of the studied children were 4.26 \pm .80 , male represented $75 \%$ while female represented $25 \%$ and $25 \%$ of the diseases were acute pneumonia with respiratory distress, chronic bronchitis, rheumatic heart disease with severe repeated chest infection respectively. while $20 \%$ of the diseases were sever dehydration complicated with pneumonia ).

Part II: The Nurses' knowledge about chest physiotherapy such as definition of chest physiotherapy, importance of chest physiotherapy, the indications, the complications of not providing chest physiotherapy and the signs and symptoms of secretions collected in the respiratory system.

Part III: (A) Nurses' knowledge related to performance and preparation for chest physiotherapy such as: the importance of checking the physician's orders identifying the patient using two identifiers, the importance of gathering the necessary equipment, the importance of hand washing and the importance of measuring the vital signs of the child frequently.

(B) Nurses' knowledge related to performance of postural drainage such as the importance of checking the physician's orders before putting the child in the suitable 
drainage position, the importance of keeping privacy of the child, how to put the child in the appropriate drainage position and the importance of documentation after performing posture drainage.

(C) Nurses' knowledge related to performance of chest percussion in chest physiotherapy such as checking the physician's orders before percussion, the importance of gathering the necessary equipment before percussion, how to perform chest percussion for the child and the importance of documentation after percussion.

(D)Nurses' knowledge related to performance of chest vibration in chest physiotherapy such as the importance of checking the physician's orders before vibration, the importance of hand washing before vibration, the importance of gathering the necessary equipment before vibration, how to perform vibration and the importance of documentation after vibration.

\section{Scoring System for Knowledge}

All knowledge questions were scored as (2) for satisfactory score of knowledge and (0) for unsatisfactory score of knowledge.

The total knowledge score was classified as the following Satisfactory: $\geq 85 \%$ of the total knowledge score \&Unsatisfactory : $<85 \%$ of the total knowledge score.

\section{Validity and reliability}

Validity and reliability of the tools:5 experts in Pediatric Nursing content to clearity test validity while, test retest was performed for reliability

\section{Ethical considerations}

Each study subject had the freedom to be involved in the study or to withdraw at any time, data was explained to the nurses and informed consent was obtained from nurses at previously mentioned settings for participation in the study before data collection ensuring complete privacy and total confidentiality

\section{Pilot study}

A pilot study was carried out on $10 \%$ ( $\mathrm{N}=5$ nurses ) of the expected sample size chosen randomly to test the tools of data collection and the applicability of the observation checklist and questionnaire, the required modifications of tools were done by adding some or omission of some questions about chest physiotherapy (participants involved in the pilot study were excluded from the study sample

\section{Field of work}

The investigator introduced her self to the nurses and dealt with them using simple arabic language. The researcher observed 1-2 nurses per visit during performing physiotherapy. The Researcher distributed the questionnaire after the observation for all the nurses in each unit. on three visits per week by the researcher during different shifts .The researcher observed the nurses during performing chest physiotherapy during their actual nursing care, then the researcher assessed nurses' knowledge about chest physiotherapy.

\section{Administrative design}

An official permission was obtained from the dean of Benha Faculty of Nursing and hospital direction of the previously mentioned settings with full explanation of the study purpose and methods of data collection

\section{Statistical design}

Data was coded and transformed into specially designed form to be suitable for computer data entry process. Data was 
manipulated and analysed using Statistical Package for Social Science(SPSS) version
22. Graphics were done by using Exell programme.

\section{Results}

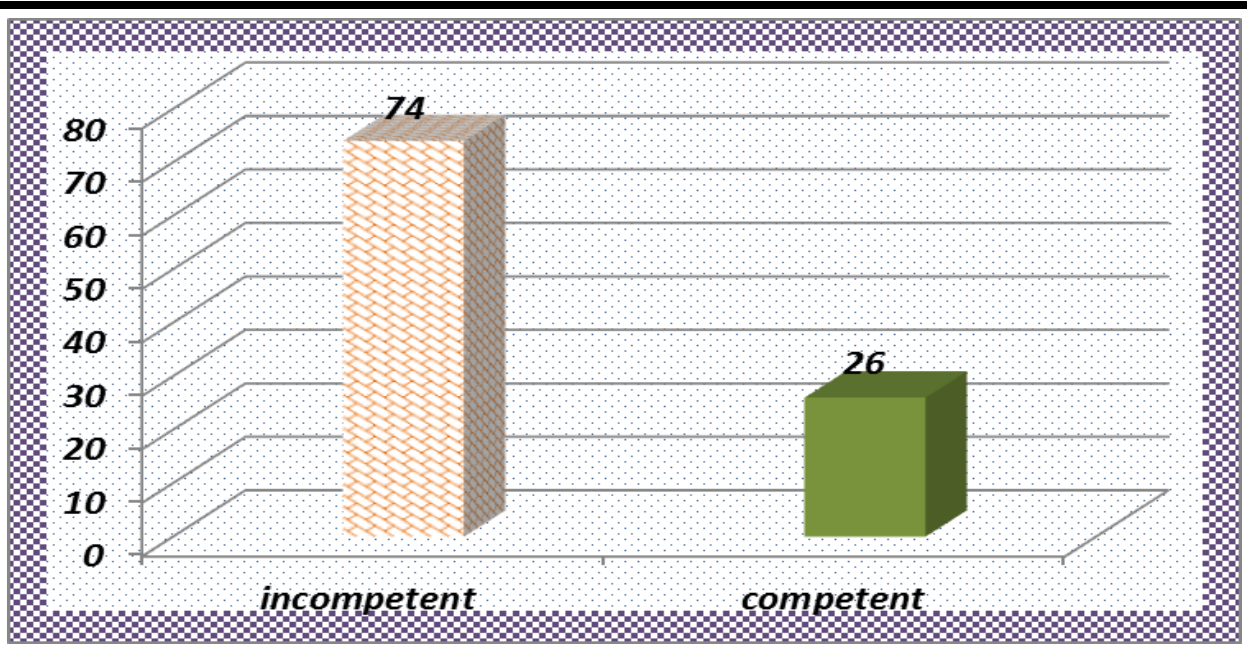

Figure (1):Distribution of the studied nurses by their total score level regarding their performance for chest physiotherapy

Figure(1): show that, $26 \%$ of the studied nurses were competent in their performance regarding to chest physiotherapy, while $74 \%$ of the studied nurses were incompetent in their performance regarding to chest physiotherapy.

Figure (2): Distribution of the studied nurses by their total score level regarding their knowledge of chest physiotherapy.

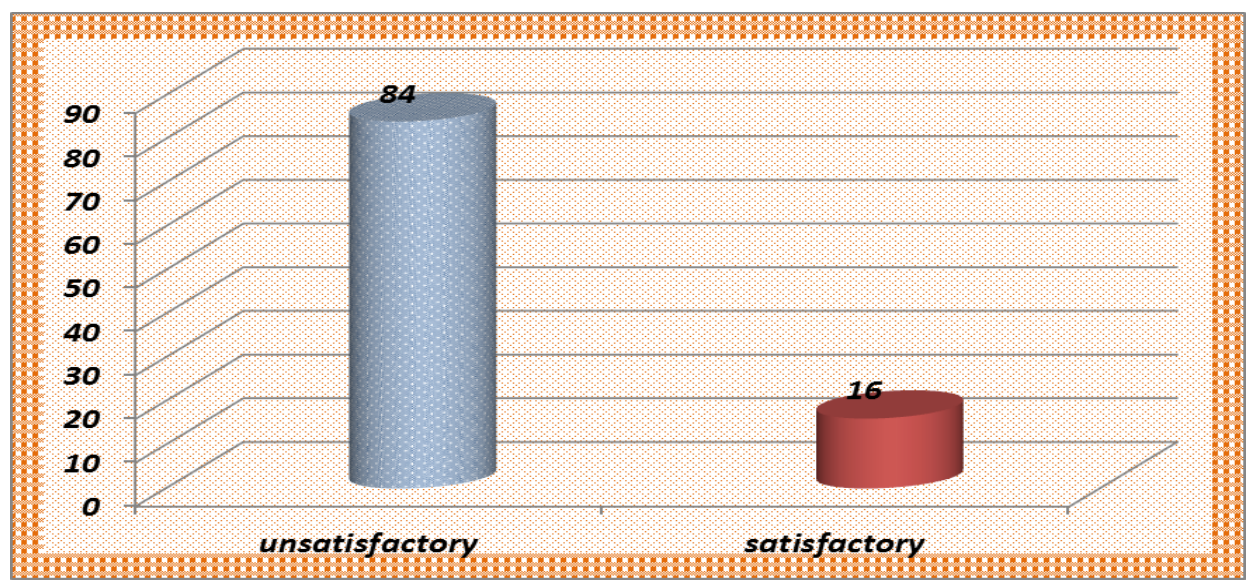

Figure(2) :show that, $16 \%$ of the studied nurses had satisfactory level of knowledge regarding chest physiotherapy, while $84 \%$ of the studied nurses had unsatisfactory level of knowledge regarding chest physiotherapy. 
Table (1): Total nurses' performance versus their total knowledge regarding chest physiotherapy.

\begin{tabular}{|c|c|c|c|c|c|c|c|}
\hline \multirow[t]{3}{*}{ Items } & \multirow{3}{*}{$\begin{array}{l}\text { Total } \\
\text { performance } \\
\text { score }\end{array}$} & \multicolumn{4}{|c|}{ Total Knowledge score } & \multirow{3}{*}{$\begin{array}{l}\text { Chi } \\
\text { square } \\
\text { test }\end{array}$} & \multirow[t]{3}{*}{ P value } \\
\hline & & \multicolumn{2}{|c|}{ satisfactory } & \multicolumn{2}{|c|}{ Unsatisfactory } & & \\
\hline & & No & $\%$ & No & $\%$ & & \\
\hline \multirow{2}{*}{$\begin{array}{l}\text { General } \\
\text { preparation }\end{array}$} & competent & 1 & $25.0 \%$ & 3 & $75.0 \%$ & \multirow[t]{2}{*}{0.262} & \multirow[t]{2}{*}{$>0.05$} \\
\hline & Incompetent & 7 & $15.2 \%$ & 39 & $84.8 \%$ & & \\
\hline \multirow[t]{2}{*}{ percussion } & competent & 1 & $20.0 \%$ & 4 & $80.0 \%$ & \multirow[t]{2}{*}{0.066} & \multirow[t]{2}{*}{$>0.05$} \\
\hline & Incompetent & 7 & $15.6 \%$ & 38 & $84.4 \%$ & & \\
\hline \multirow[t]{2}{*}{ Vibration } & competent & 1 & $20.0 \%$ & 4 & $80.0 \%$ & \multirow[t]{2}{*}{0.066} & \multirow[t]{2}{*}{$>0.05$} \\
\hline & Incompetent & 7 & $15.6 \%$ & 38 & $84.4 \%$ & & \\
\hline \multirow[t]{2}{*}{ postural drainage } & competent & 8 & $17.0 \%$ & 39 & $83.0 \%$ & \multirow[t]{2}{*}{0.608} & \multirow[t]{2}{*}{$>0.05$} \\
\hline & Incompetent & 0 & $0.0 \%$ & 3 & $100.0 \%$ & & \\
\hline \multirow[t]{2}{*}{ Total performance } & competent & 2 & $15.4 \%$ & 11 & $84.6 \%$ & \multirow[t]{2}{*}{0.005} & \multirow[t]{2}{*}{$>0.05$} \\
\hline & Incompetent & 6 & $16.2 \%$ & 31 & $83.8 \%$ & & \\
\hline
\end{tabular}

Table(1):shows that, $75 \%$ of the studied nurses were competent but had unsatisfactory knowledge regarding preparation for chest physiotherapy, while $80 \%$ of the studied nurses were competent but had unsatisfactory knowledge regarding percussion and vibration, $83 \%$ of the studied nurses were competent but had unsatisfactory knowledge regarding postural drainage, $84.6 \%$ of the studied nurses were competent regarding their total performance but had unsatisfactory knowledge regarding their total knowledge, also it's clear from the same table that there was no statistical significant between the total nurses' performance and their knowledge in all the procedures (General preparation, Percussion, Vibration and postural drainage) regarding chest physiotherapy.

Table (2): Correlation between total performance and total: knowledge score of the studied nurses.

\begin{tabular}{|c|c|c|}
\hline \multirow{2}{*}{ Variables } & Total performance score & \multirow{2}{*}{ P value } \\
\cline { 2 - 3 } & $\mathbf{r}$ & \\
\hline Total knowledge score & .2 & $>0.05$ \\
\hline
\end{tabular}

Table (2): reveals that, there were a positive correlation between total knowledge score and total performance score of the studied nurses $(\mathbf{r}=.2$ at $\mathbf{P}$ value $>0.05)$.

\section{Discussion}

The current study revealed that three quarters of the studied nurses their age less than 20 years, the studied nurses mean age were $(28.02 \pm 4.36)$ years. This result was similar to the results performed by $\mathbf{A l i}$, (2014) in a study entitled "knowledge versus their performance in caring for neonates having respiratory distress syndrome", who found that, the more half of the studied nurses were less than 20 years.
Regarding characteristics of the studied children. The results of the present study illustrated that, half of the studied children were at age group $3<4$ years with the mean age was \pm SD: $(4.28 \pm .80)$ this finding similar to Abd El-Samiea, (2014) in a study entitled "nurses' performance regarding care of children undergoing cardiac surgery "Who found that, more than half of the studied children were at age group $3<4$ years with the mean age was $\pm \mathrm{SD}(4.5 \pm 0.6)$.

The result of the current study revealed that two third of the studied children were male. This result was agreed with 
Mahmoud, (2011)in a study entitled "physiotherapeutic technique performed by nurses to children in intensive care units "who stated that, more than half of the studied children were male.

Regarding nurses' performance about postural drainage. The results of the current study revealed that the majority of the studied nurses had incompetent score of performance regarding to place child in appropriate postural drainage. In agreement with $\boldsymbol{A b d} \boldsymbol{E l}-\boldsymbol{A z \boldsymbol { i z }},(2001)$ in a study entitled "Assessment of nursing giving to children under mechanical ventilation" who found that the majority of nurses neglected to place child in appropriate position during chest physiotherapy procedures.

Regarding nurses' performance regarding chest percussion. The finding of present study found that, the majority of the studied nurses had incompetent score of performance regarding used two identifiers to identify the child. This finding was disagreed with Ahmed, (2012)in a study entitled" Quality of Nursing Intervention provided to Infants Receiving Mechanical Ventilation" who found that the majority of the studied nurses hadn't used the identifiers to identify the infant.

In relation of the studied nurses' performance regarding chest vibration. The present study results found that, the majority of the studied nurses had incompetent score of performance regarding to prepare basic equipment of chest vibration. This result consistent with $\mathbf{A l i}$, (2014) who found that the majority of the studied nurses hadn't prepare the equipment of vibration procedure.

The current study found that, more than two third of the studied nurses had incompetent level of their total performance score regarding to chest physiotherapy. This result may be due to lack of attending programs about chest physiotherapy. This result was supported with Hussein,(2012)in a study entitled "ventilator - associated pneumonia among children. nurses' knowledge and practice "who found that the majority of the studied nurses had incompetent of total performance score of chest physiotherapy. In contrast $\boldsymbol{A b d} \boldsymbol{E l}$ Hameed, (2013) in a study entitled "Monitoring quality of care of neonate with respiratory distress" who found that more than half of the studied nurses had competent of total performance score about chest physiotherapy.

Regarding Relation between the studied nurses' total performance scores and their qualification level, it revealed that, there was highly statistical significant relation between nurses' performance and their qualification level $\left(\mathrm{P}<0.05^{*}\right)$. this finding reflected that nurses with bachelor degree had better degree than diploma. It was supported by Mahmoud, (2011) who found that there was highly statistically significant between total nurses' performance score and their education level.

Regarding nurses' knowledge regarding chest physiotherapy. The result of the present study showed that, All of the studied nurses had poor knowledge regarding to definition and indication of chest physiotherapy. This result may be due to the majority of the studied nurses had less experience and lack of attending training programs about chest physiotherapy. This result was a greed with Ahmed, (2012) as the majority of the studied nurses had incomplete answer about the definition of chest physiotherapy and more than two third of them had incomplete answer about the indication of chest physiotherapy.

Regarding studied nurses' knowledge about postural drainage the findings of the present study revealed that, all of the studied nurses had poor knowledge regarding to the 
types of the postural drainage. This result may be due to lack of having training programme of chest physiotherapy. This finding was contracted with Sadek, (2010) In a study entitled "Evidence Based Guidelines for care of neonates with respiratory distress " who found that the majority of the studied nurses had poor knowledge about postural drainage

Regarding nurses' knowledge about chest percussion. The results of the current study revealed that, more than three quarters of the studied nurses had poor knowledge regarding preparing the basic equipment of percussion. In the same line, Ali, (2014) who found that, the majority of the studied nurses had correct answer about Basic equipments of percussion.

Regarding nurses' knowledge about using nurses cupped hand in performing chest percussion. The findings of the present study revealed that, the majority of the studied nurses had good knowledge regarding using cupped hand in performing percussion. this finding was disagree with Ali, (2014) who found that, more than two third of the studied nurses had incorrect answer about using cupped hand in doing percussion.

Regarding studied nurse' knowledge about vibration, the current study's results revealed that, the majority of the studied nurses had poor knowledge about using open (Flat) hand in performing vibration. This result was paralleled with $\boldsymbol{A l i}$, (2014) Who found that, more than half of the studied nurses had poor knowledge about using open hand in vibration. .

The current study's results revealed that more than three quarters of the studied nurses had unsatisfactory level of knowledge regarding to chest physiotherapy. This may be attributed to nurses' educational level, lack of in-service training, inadequate administration strategies and there is no system in hospital to encourage nurses to update their knowledge and practice. This result was agreed with Mahmoud, (2011), who found that, more than half of the studied nurses had poor knowledge about chest physiotherapy.

Regarding relation between of the studied nurses' total knowledge scores and their qualification level This result study revealed that, there was statistically significant relation between nurses' knowledge and their qualification $(\mathrm{P}<0.05)$ this result could be interpreted as nurses with bachelor and technical nursing education had more knowledge than nurses with diploma degree this finding was supported by Mahmoud, (2011) who found that there was high statistically significant relation between nurse's academic qualification and total knowledge scores $\left(\mathrm{P}<0.05^{*}\right)$.

Regarding correlation between the studied nurses' total knowledge scores and their total performance scores. These study results revealed that, there was a positive correlation between of the studied nurses' total knowledge scores and their total performance scores $(\mathrm{R}=0.200, \mathrm{P}=>0.05)$. this finding supported by Mahmoud , (2011) who reported that, there was a positive significant correlation between total knowledge and total practice score of the studied nurses.

\section{Conclusion:}

Pediatric Intensive Care unit nurses had unsatisfactory knowledge \&incompetent during performing chest physiotherapy, there was highly statistical significant relation between nurses' performance and their qualification only. While there was highly statistical significant relation between nurses' knowledge and nurses' age, qualification and years of experience. 


\section{Recommendation:}

1-Upgrading Pediatric Nurses Intensive Care knowledge and performance regarding to chest physiotherapy through continuous, in service and in job training education program.

2-Further studies about chest physio therapeutic techniques performed by nurses to children in Pediatric Intensive Care Units at different settings .

\section{References}

Abd El_Aziz A. (2001): Assessment of Nursing Care Given to Children under Mechanical Ventilation. Master thesis, Faculty of Nursing Ain Shams University P. 73.

Ahmed,S. (2012):Quality of Nursing Interventions Provided to Infants Receiving Mechanical Ventilation. Master Thesis, Faculty of Nursing , Tanta Univessity . Pp.56-65-66-68-95.

Abd El-Hameed ,A. (2013) :Monitoring quality of Care of Neonate with Respiratory Distress . Master Thesis , Faculty of Nursing, Ain Shams University , p. 116.

.Ali ,A.E. (2014) : Nurses' Knowledge Versus their performance in caring for Neonates Having Respiratory Distress Syndrome. Doctrate Thesis, Faculty of Nursing, Ain Shams University, Pp . 5694-135.

Abd El-Samiea,A. (2014): Nurses' Performance Regarding Care of children undergoing Cardiac Surgery. Master Thesis , Faculty of Nursing ,Tanta University . p. 71.
Ellie and Jones. (2015):What is the role of the physiotherapist in paediatric intensive care units? Physiotherapy journal. Volume 101, Issue 4, pp 303-309

El-Sayed ,F.E. (2012): Assessment of Nursing Care Given to Children with Pneumonia. Master Thesis, Faculty of Nursing, Ain Shams University, Pp. 91104

Hussein,A.S. (2012): Ventilators _Associated Pneumonia Among children, Nursing Knowledge and Practice . Master Thesis, Faculty of Nursing . Ain Shams University, p. 92.

James, R. (2016): Airway Clearance Therapy. The Comprehensive Respiratory Therapist Exam Review. Country. Indian.co. ,Elsevier Health Sciences $.6^{\text {th }}$ ed 2016. 10:pp278-305.

Jennifer,M.; Nelin ,K and Jennifer, K(2013) : Cardiopulmonary Physical Therapy Practice in the Paediatric Intensive Care Unit .Physiotherapy Canada ; 65(4) 374377.

Mahmoud , A. (2011): Physiotherapeutic Technique Performed by Nurses to children in Intensive $\mathrm{C}$ are units .Master thesis ,Faculty of Nursing ,Zagazig University,pp.51-52-58.,

Marry K. and Patrick, A . (2009): AirwayClearance Therapy Guidelines and Implementation. respiratory CARE ; 54 (6) : 733 - 753. bronchiectasis.". American Journal of Respiratory and Critical Care Medicine: 188 (6): pp 64756.

Mitra P. (2008):Techniques of Physical Therapy Treatment in Respiratory Disorders, Handbook of Practical Chest Physiotherapy, JAYPEE The Health 
Nashat E.Ali , Osama A.El fik; Madiha A. Morsy;Basma R.Abd El sadek

Care Publisher. $1^{\text {st }}$ edition' : 7, pp 110148 .

Jerithea and Brennan, (2017):Pediatric Critical Care, An Issue of Critical Nursing Clinics, Critical Care Nursing Clinics of North America . 1st Edition. ; 29-2 : pp 3-25

Patricia A. Potter.; Anne Griffin P.; Patricia.; and Hall. (2017): Foundations for
Nursing Practice. Fundamentals of Nursing, 9th Edition. 5: pp 422-630.

Sadek,B. N. (2010):Evidence Based Guidelines for Care of Neonates with Respiratory Distress. Doctorate thesis. Faculty of Nursing Ain Shams University , p. 118

Stiller ,K. (2013): Physiotherapy in intensive care: An updated systematic review. Chest $\quad ; 144$ : pp $\quad 825-47$ 